\title{
Profile of patients attended by the speech therapists of the home care service
}

\author{
Suelene Castro de Figueiredo(1) \\ Rebecca Rhuanny Tolentino Limeira ${ }^{(1)}$ \\ Laís Guedes Alcoforado de Carvalho(1) \\ Renato de Carvalho Morais Junior(2) \\ Isabella Lima Arrais Ribeiro(1) \\ Simone Pereira Lins Chaves ${ }^{(3)}$ \\ Marcela Leiros Maciel Macedo ${ }^{(4)}$ \\ Ricardo Dias de Castro(1)
}

1) Universidade Federal da Paraíba - UFPB, João Pessoa, Paraíba, Brasil.

(2) Centro de Especialidades Odontológicas - CEO, João Pessoa, Paraíba, Brasil.

(3) Serviço de Atenção Domiciliar, Prefeitura Municipal de João Pessoa, João Pessoa, Paraíba, Brasil.

(4) Centro de Atenção Psicossocial - CAPS Infantil, Prefeitura Municipal do Recife, Recife, Pernambuco, Brasil.

Conflict of interests: Nonexistent

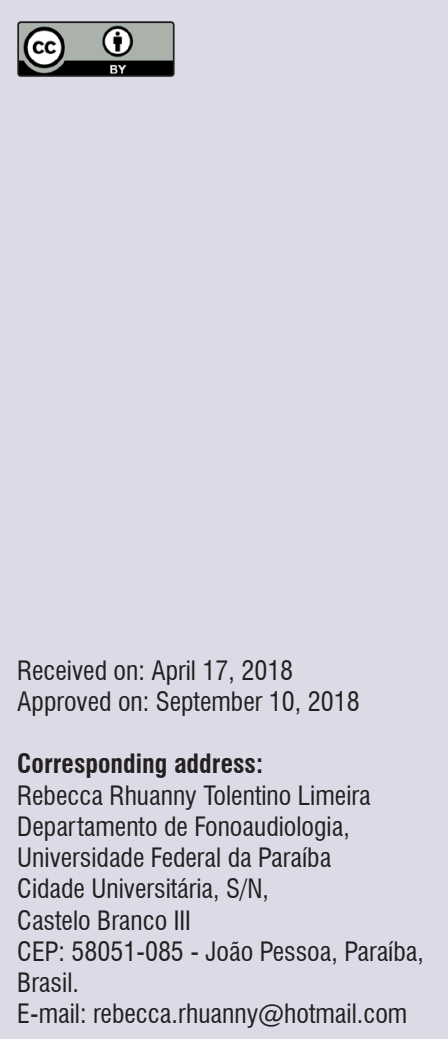

\section{ABSTRACT}

Objective: to ascertain the profile of home care service (HCS) users with speech and language complaints in João Pessoa, Paraíba (PB).

Methods: a descriptive and quantitative study using an indirect documentation technique based on an analysis of primary source documents, characterized as a documentary study, conducted at a HCS, in João Pessoa, PB, that stores user information in the form of medical records. All patient records included by the HCS from June 2012 to June 2016 were analyzed. After the eligibility criteria were applied, the sample consisted of 114 medical records. The collected data were entered into a Microsoft Excel spreadsheet to generate descriptive statistics using IBM SPSS (version 21.0).

Results: most patients were males (59.6\%), elderly (62.3\%), had been diagnosed with a stroke (57.9\%),had histories of dysphagia (76.3\%), speech problems $(58.8 \%)$, swallowing disorders (80.7\%), and abnormal chewing (77.2\%). Dysphagia is often associated with stroke, predominantly among males and the elderly.

Conclusion: difficulty in swallowing, or dysphagia, is often associated with stroke, predominantly in the presence of the sociodemographic and clinical variables associated with men and the elderly.

Keywords: Home Care Service; Primary Healthcare; Speech, Language and Hearing Sciences 


\section{INTRODUCTION}

According to the Brazilian Institute of Geography and Statistics (Instituto Brasileiro de Geografia e Estatística; IBGE), over the past few years, Brazil has shown a new demographic pattern characterized by a reduction in population growth and changes in its age composition, with a significant increase in the elderly population. Because of these changes, important developments have occurred in the population's epidemiological profile, including changes in morbidity and mortality indicators ${ }^{1-4}$.

Healthcare systems in various parts of the world refer to the difficulty associated with providing effective and continued care to individuals with chronic diseases ${ }^{5-7}$. The United States has launched certain reforms, but gaps remain, particularly regarding the centralization of care in medical practices, hospitals, and nursing homes ${ }^{5}$.In light of this reality, one study conducted in England used projections to estimate the demand that will be needed to monitor and assist dependent individuals over the next 80 years ${ }^{7}$.

In this context, the incorporation of non-traditional modes of healthcare production is noteworthy. Examples of home palliative care in Brazil include the Family Health Strategy (Estratégia Saúde da Família; ESF) and the Home Care Service (HCS). However, the registration and systematisation of these services is scarce, in both the private and public spheres ${ }^{2,8}$.

The implementation of the HCS arose from the need to reduce costs and increase user satisfaction. The HCS also aims to increase the number of available hospital beds, reduce the risk of infection, and increase the humanisation of care. Therefore, it is a strategy with a strong focus on minimising hospitalisation through on-going home care ${ }^{9}$.

Under the Brazilian Unified Health System (Sistema Único de Saúde; SUS), the HCS plays a complementary role to hospitalisation and outpatient care, and it is focused on humanised care. To this end, actions are undertaken with regard to treatment, prevention, and health promotion to rehabilitate patients in their homes and ensure that the same care provided in-hospital is received on an on-going basis. Analysing the health and disease process is essential for guiding quality practices consistent with the social reality in which healthcare professionalsoperate $e^{2,10,11}$.

This service is the responsibility of the Multidisciplinary Home Care Team (Equipe Multiprofissional de Atenção Domiciliar; EMAD), which is composed of a nurse, physical therapist, doctor, and four nursing technicians, and the MultiProfessional Support Team (Equipe Multiprofissional de Apoio; EMAP), which is composed of a social worker, pharmacist, speech therapist, nutritionist, and psychologist $^{12-14}$.

HCSs have been implemented in several countries because of epidemiological and demographic changes primarily related to the rational use of hospital beds to reduce costs and improve humanised care ${ }^{4,15}$.

However, few Brazilian studies have addressed the data related to users with speech and language complaints aiming to observe the success achieved via the implementation of such a programme at the municipal level to improve the logic of and seeking greater efficiency in HCS. Therefore, this study aimed to determine the social and clinical profiles of users with speech and language complaints of anHCSin João Pessoa, PB, Brazil.

\section{METHODS \\ Ethical aspects}

In accordance with National Research Council Resolution 466/2012, this research project was submitted in advance to the ethics committee of the source institution and was approved under CAAE protocol number 445851715.9 .0000 .5188 .

\section{Study design}

This cross-sectional, descriptive, andquantitative study used an indirect documentation technique based on an analysis of primary source documents. As such, the current work is characterised as a documentary study. Variables were collected regarding sociodemographic characteristics, clinical diagnosis, deleterious oral habits, and speech and languageconditions.

\section{Sample}

The medical records of 846 HCS users from June 2012 to June 2016 in João Pessoa, PB, were analysed. Patients with speech and language complaints were eligible for the study; as such, 114 participants were selected after the records had been analysed.

\section{Data collection}

Data were collected from the municipal health office of João Pessoa, PB,in conjunction with the Office of Labour Management and Health Education. 
Two previously trained researchers analysed the records at the service itself in a private environment. The collected data were recorded on a form designed for this purpose.

The variables of interest included gender, age, clinical diagnosis, reason for consultation, speech therapy observations, speech and language conditions, and diagnosis.

\section{Data analyses}

The collected data were entered into a Microsoft Excel spreadsheet to generate descriptive statistics using IBM SPSS (version 21.0).

\section{RESULTS}

A total of $114 \mathrm{HCS}$ users with speech and language complaints were treated between June 2012 and June
2016. Most of the treated patients were men ( $n=68$; $59.6 \%)$; most were elderly ( $n=71 ; 62.3 \%)$; and stroke was the major clinical diagnosis found ( $n=66 ; 57.9 \%$ ). The main reason for attending the speech therapy clinic was dysphagia ( $n=87 ; 64.9 \%)$. The remaining demographic profile information is shown in Table 1.

Speech and language disorders were evaluated. The following conditions were most prevalent: swallowing ( $n=92 ; 80.7 \%)$, dentition ( $n=92 ; 80.7 \%)$, and chewing $(n=88 ; 77.2 \%)$. A speech and language condition analysis revealed that most users did not require artificial respiration $(\mathrm{n}=101 ; 88.6 \%)$ and received food orally $(n=92 ; 80.7 \%)$.The diagnosis performed by the HCS's speech therapists revealed that dysphagia ( $\mathrm{n}=59 ; 51.8 \%$ ) and oral myofunctional disorder $(n=11 ; 9.6 \%)$ were the most prevalent conditions during the evaluated time period (Table 2).

Table 1. Sociodemographic and clinical diagnostic variables as well as the reason for speech and language therapy consultation among users treated by the HCS from 2012 to 2016, João Pessoa, PB, Brazil $(n=114)$

\begin{tabular}{ccc}
\hline Variables & N & $\%$ \\
\hline Gender & & 59.6 \\
Males & 68 & 40.4 \\
Females & 46 & 0.9 \\
Age group & 1 & 3.5 \\
Child & 4 & 31.6 \\
Adolescent & 36 & 62.3 \\
Adult & 71 & 1.8 \\
Elderly & 2 & 57.9 \\
Not reported & & 3.5 \\
Clinical diagnosis & 66 & 2.6 \\
Stroke & 4 & 1.8 \\
Cerebral palsy & 3 & 1.8 \\
Parkinson's & 2 & 31.5 \\
Hypertension & 2 & \\
Mental impairment & 36 & 76.3 \\
Others & & 64.9 \\
\hline Reason for consultation & 87 & 58.8 \\
History of dysphagia & 74 & 52.6 \\
Weight loss & 67 & 18.4 \\
Speech problems & 60 & 14.9 \\
Soft food & 21 & \\
Pneumonia & 17 &
\end{tabular}


Table 2. Speech therapy profile of the users treated by a HCS from 2012 to 2016 in João Pessoa, PB, Brazil $(n=114)$

\begin{tabular}{|c|c|c|}
\hline Variables & $\mathbf{n}$ & $\%$ \\
\hline \multicolumn{3}{|l|}{ Speech therapy observations } \\
\hline Does not need respiratory support & 101 & 88.6 \\
\hline Feeding by oral route & 92 & 80.7 \\
\hline Conscious & 84 & 73.7 \\
\hline Soft food & 60 & 52.6 \\
\hline Somnolent & 22 & 19.3 \\
\hline Need for food thickener & 17 & 14.9 \\
\hline Nasoenteral feeding (NET) & 12 & 10.5 \\
\hline Use of intermittent oxygen therapy & 4 & 3.5 \\
\hline Nasogastric feeding (NGT) & 2 & 1.8 \\
\hline \multicolumn{3}{|l|}{ Speech and language disorders } \\
\hline Swallowing & 92 & 80.7 \\
\hline Dentition & 92 & 80.7 \\
\hline Chewing & 88 & 77.2 \\
\hline Cheeks & 83 & 72.8 \\
\hline Articulation & 81 & 71.1 \\
\hline Lips & 77 & 67.5 \\
\hline Voice quality & 55 & 48.2 \\
\hline Suction & 54 & 47.4 \\
\hline Cough & 28 & 24.6 \\
\hline Gag reflex & 26 & 22.8 \\
\hline Soft palate & 10 & 8.8 \\
\hline \multicolumn{3}{|l|}{ Diagnosis } \\
\hline Dysphagia & 59 & 51.8 \\
\hline Orofacial myofunctional disorder & 11 & 9.6 \\
\hline Aphasia and dysphagia & 11 & 9.6 \\
\hline Dysphagia and orofacial myofunctional disorder & 10 & 8.8 \\
\hline Aphasia & 6 & 5.3 \\
\hline Not reported & 6 & 5.3 \\
\hline Stroke & 3 & 2.6 \\
\hline Aphasia and orofacial myofunctional disorder & 2 & 1.8 \\
\hline Dysphagia, aphasia, and orofacial myofunctional disorder & 2 & 1.8 \\
\hline Normal & 2 & 1.8 \\
\hline Dysarthria & 2 & 1.8 \\
\hline
\end{tabular}

\section{DISCUSSION}

This study is justified by the lack of investigations of this nature in Brazil and because knowledge of this population can contribute to health service planning processes and evaluation. Such planning and evaluation processes are basic steps when developing a healthcare programme that aims to increase the effectiveness of its actions and seeks to expand and qualify care. Therefore, knowing the profile of the users who will receive this care is critical to the development of the (often interdisciplinary) intervention protocols that meet the real needs of this population ${ }^{15}$. In addition, the current results have scientific relevance because they support improvementsin research and prevention programmes, thereby enhancing the work of primary care managers and professionals.

For Silva et al. ${ }^{8}$, home care constitutes a concrete strategy for establishinga substitutive network by producing new modes of care that meet the expectations of users, families, social networks, and workers. Home care requires political, conceptual, and operational sustainability as well as the recognition of new 
ways of organising and coordinating the proposals under discussion. Therefore, it isnecessary to considerelements such as comprehensive healthcare, financial economic rationality, the participants of care, and coordination with other services.

From the point of view of the population's need for speech therapy services, children's oral language disorders have been the most researched, in terms of both family health teams and the actions aimed at the development of sensory-motor-oral system functions. In these cases, a perspective of promotion and disease prevention is preferable ${ }^{16}$.

According to Molini-Avejonas, Mendes, and Amato $^{12}$, the role of speech therapy in public health services is extensive and permeates different levels of care. Therefore, it requires teamwork marked by the use of healthcare technologies that consider the real needs of the population within both basic and specialised care. For these authors, it is necessary to advance the production and systematisation of the healthcare processes that are able to respond to severe language, voice, oral motor skills, and hearing disorders. Therefore, monitoring and evaluative systematisation should contribute to a comprehensive healthcare strategy.

It is in this plural context of healthcare intervention that home care services have emerged as another strategy to expand healthcare coverage. These services aim to reduce unnecessary hospitalisation previously caused by weak support; minimisethe complications caused by prolonged hospitalisation, thereby increasing the turnover of hospital beds; and promote palliative care where pain relief and a good death can be a part of the health team's work. These practices can be developed even in economically disadvantaged environments and contribute to the provision of integrated and on-going care ${ }^{17,18}$.

The sociodemographic results for the HCS users revealed a prevalence of men (59.6\%) and elderly individuals (62.3\%), confirming the findings of other studies in the literature ${ }^{4,19,20}$. These studies show that married elderly white men with incomplete primary school education predominate $e^{4,19,21}$. However, another national study found that home care users tended to be women with chronic diseases and functional disabilities $^{21}$. Therefore, the data found might be associated with the epidemiological profile typical of each region. Furthermore, the predominance of the elderly is explained by disability caused by the morbidities that affect this age group.

Most of the patients who attended the HCS in João Pessoa, PB, were elderly. This result is consistent with past research ${ }^{19,20,22}$. These data are related to the increase in life expectancy and chronic disease associated with this age group. This finding underlines the importance of home care, especially given the movement restrictions that the majority of these patients experience due to senescence. The literature review of Ferreira, Bansi, and Paschoa (2014) ${ }^{22}$ described the HCSin relation to user demand, healthcare flow, and service management. They found that the demand for elderly care is increasing due to population ageing ${ }^{22}$.

This study shows that the use of home care has increased, primarily among the more vulnerable elderly individuals affected by chronic morbidity. In a population-based study that evaluated the prevalence and factors associated with home healthcare in the elderly, Wachs et al. (2016) ${ }^{4}$ found that the HCS had contributed to the promotion of equity in Brazilian healthcare via the expansion of the ESF.

The results of the present study revealed that strokes were most common, which corroborates the findings of other studies conducted in Brazil 18,19,22 and elsewhere according to Baumann et al. (2014) ${ }^{23}$. Importantly, stroke survivors are often unable to perform routine activities and suffer communication (e.g., language, writing, and speaking) and body mobility disorders. This effect is reflected in major changes to these patients' quality of life and requires appropriate and multidisciplinary treatment ${ }^{20,24}$. In addition, the importance of developing public policies such as home care that aims to improve quality of lifeis emphasised ${ }^{4,19,23,25}$.

Patients treated within the HCS generally have multiple conditions and require multidisciplinary treatment. In addition, because of the chronic nature of the pathologies presented by these patients, the duration of on-going care must be increased, confirming the need for a service that focuses on caring for the patient in his or her home ${ }^{18}$. Ferreira et al. $(2014)^{22}$ proposed a model of elderly healthcare that aims to provide effectiveness, efficiency, and actions involving all levels of care, including the prevention of, and rehabilitation from, health issues.

In addition, the majority of those evaluated did not require respiratory support, were able to take in food orally, and were conscious. Oral feeding remains more 
prevalent even after the onset of morbidities such as stroke and cerebral palsy, which were the most prevalent forms found in this study. This result has also been found by other studies ${ }^{23,24}$, but future studies should evaluate the degree of disease severityto facilitate response and improvement in particular situations where oral feeding remains limited.

Regarding the reasons for attending speech therapy, dysphagia, weight loss, and the loss of speech were the most prominent. This result confirms the findings of Paixão $(2010)^{19}$, who explained that dysphagia affects weight loss due to the patient's inability to eat normally.

Based on the data evaluated by this study, only stroke reached a significant level, and most of the evaluated individuals did not require respiratory support and orally consumed soft food. Therefore, care should be taken given that the variables are closely related because swallowing disorders are reflected in chewing difficulties. Because of these conditions, it is necessary to emphasise the importance of an exclusive diet for dysphagia because many of these patients can inhale or experience the laryngeal penetration of food due to inappropriate food consistency ${ }^{25}$.

As such, the elderly might be more prone to dysphagia after a stroke. Records reveal a greater incidence of dysphagia among elderly patients, noting a relationship between dysphagia and age. The swallowing process as a whole is affected by age, with general changes in the characteristics of this function. Older patients are prone to initial swallowing problems, with an increased mortality rate ${ }^{19}$.

In this context, the present study found that the demand for institutional care tends to increase due to population ageing. Multidisciplinary teams are essential to the functioning of the services described. Professionals should be able to offer care according to the demands of the elderly and the type of service offered, especially for an older and fragile population, via the services reviewed ${ }^{18,26}$.

Finally, the presence of the speech therapist in the public network (SUS) has propitiated a change incontext because clinical and therapeutic care, which previously was private and restricted to the consulting room, has been adapted to the new institutional realities, and its perspectives and range of activities have expanded. One of these activities is operating in the home environment via public home care programmes and policies that can be implemented and embraced by all other healthcare professionals because in this type of activity, the professional develops activities that facilitate health promotion, prevention, and rehabilitation in the home.

Because the home care guidelines are comprehensive and easily adaptable to the needs of each municipality or region, the roles of speech therapists and other health professionals cangreatly vary according to the type of intervention to be performed and the degree of case complexity. As such, the presence of an acting speech therapist or healthcare professional should become increasingly common in Brazil.

According to the profile of the users treated in this service, the importance of including speech therapists is apparent to emphasise the investment in the improvement and enrolment of both professionals and patients. Therefore, it isimportant that new studies are undertaken to facilitate the understanding of healthcare professionals and managers with regard to the topic in question.

\section{CONCLUSION}

The results obtained allow us to conclude that difficulty in swallowing (i.e., dysphagia) is often associated with stroke, predominantly with regard to the sociodemographic and clinical variables associated with males and the elderly. This fact demonstrates the importance of including speech therapy in the HCS Programme of João Pessoa, PB, Brazil, to maintain patient health and quality of life.

\section{REFERENCES}

1. Brasil. Instituto Brasileiro de Geografia e Estatística (IBGE). Indicadores sociodemográficos e de saúde no Brasil 2009 Disponível em: http://www.ibge. gov.br/home/estatistica/pesquisas/pesquisas.php Acesso em: 24 marc. de 2016.

2. Braga PP, Sena RR, Seixas CT, Castro EAB, Andrade AM, Silva YC. Supply and demand in home health care. Cien Saude Colet. 2016;21 (3):903-12.

3. Alves DB, Barbosa MTS. Desigualdades na mortalidade por doenças crônicas entre idosos e sua associação com indicadores socioeconômicos no Brasil. Rev Bras Cien Envelh Hum. 2010;7(1):22-33.

4. Wachs LS, Nunes BP, Soares MU, FaCchini LG, Thumé E. Prevalence of home care and associated 
factors in the Brazilian elderly population. Cad Saude Publica. 2016;32(3):1-9.

5. Dejonge KE, Taler G, Boling PA. A independence at home: community-based care for older adults with severe chronic ilness. Clinics in geriatric medicine. 2009;25(1):155-69.

6. Dubuc N, Dubois MF, Raîche M, Gueye NDR, Hébert R. Meeting the home-care needs of disabled older persons living in the community: does integrated services delivery make a difference? BMC Geriatrics. 2011;11(1):67.

7. Jagger C, Collerton JC, Davier K, Kingson A, Robinson LA, Eccles MP et al. Capability and dependency in the Newcastle 85+ cohort study. Projections of future care needs. BMC geriatrics. 2011;11(1):1-11.

8. Silva KL, Sena RR, Seixas CT, Feuerwerker LCM, Merhy EE. Home care as change of the technical-assistance model. Rev Saude Publica. 2011;44(1):166-76.

9. Fontoura VT, Arend SC. Redes organizacionais como alternativa para gestão hospitalar: o sindicato dos hospitais beneficentes, religiosos e filantrópicos do Vale do Rio Pardo (SINDHVARP). Rev Desenvolv Reg. 2015;12(1):129-47.

10. Ministério da Saúde. Portaria oo 2.527 de 27 de outubro de 2011. Redefine a Atenção Domiciliar no âmbito do Sistema Único de Saúde (SUS). Diário Oficial [da] União, Brasília, 2011. Disponível em: <http://bvsms.saude.gov.br/bvs/saudelegis/ gm/2011/prt2527_27_10_2011.html >. Acesso em: Acesso em: 10 maio de 2016.

11. Moreira TNF, Martins CL, Feuerwerker LCM, Schraiber LB. The foundation of care: Family Health Program teams dealing with domestic violence situations. Saude Soc. 2014;23(3):609-15.

12. Panizzi M, Lacerda JTD, Natal S, Franco TB. Productive restructuring in health: performance and challenges of the Family Health Support Center. Saude Debate. 2017;41(112):155-70.

13. Evangelista MS, Alencar VA, Veneziano WH, Martins EF. Definition of essential data to software which will point out the de hospitalization conditions for home care. Rev Eletron de Comun Inf Inov Saúde. 2015;9(3):1-13.

14. Souza ICP, Silva AG, Quirino ACS, Neves MS, Moreira LR. Profiles of dependent hospitalized patients and their family caregivers: knowledge and preparation for domiciliary care practices. Rev Min Enferm. 2014;18(1):164-72.

15. Szebehely M, Trydegard GB. Home care for older people in Sweden: a universal model in transition. Health Soc Care Community. 2012;20(3):300-9.

16. Zanin LE, Albuquerque IMAN, Melo DH. Speech, language and hearing sciences and the family health strategy: implication of structural dimension in the quality of speech, language and hearing care. Audiol Commun Res. 2015;20(3):255-61.

17. Lima EDFA, Sousa MHDN, Primo CC. Evaluation of the Family Healthcare Strategy from the Perspective of Health Professionals. Escola Anna Nery. 2016;20(2):275-80.

18. Lima ACMAC, Silva AL, Guerra DR, Barbosa IV, Bezerra KC, Oriá MOB. Nursing diagnoses in patients with cerebral vascular accident: an integrative review. Rev Bras Enferm. 2016;69(4):785-92.

19. Paixão CT, Silva LD, Camerini FG. Profile of dysphagia after a stroke: an integrative review. Rev Rene. 2010;11(1):181-90.

20. Gaspar MRF, Pinto GS, Gomes RHS, Santos RS, Leonor VD. Evaluation of quality of life in patients with neurogenic dysphagia. Rev. CEFAC. 2015;17(6):1939-45.

21. Barros MBA, Francisco PMSB, Zanchetta LM, César CLG. Trends in social and demographic inequalities in the prevalence of chronic diseases in Brazil. PNAD: 2003- 2008. Cien Saude Colet. 2011;16(9):3755-68.

22. Ferreira FPC, Bansi LO, Paschoal SMP. Aged care services and home health care and institutional strategies. Rev Bras Geriatr Gerontol. 2014;17(4):911-26.

23. Carnaúba MD, Silva TDA, Viana $F$, Alves JBN, Andrade NL, Trindade Filho EM. Clinical and epidemiological characterization of patients receiving home care in the city of Maceió, in the state of Alagoas, Brazil. Rev Bras Geriatr Gerontol. 2015;20(3):353-63.

24. Biscione FM, Szuster D, Ferreira G, Turci MA, Lima Júnior LF, Drumond $E$ et al. Home care effectiveness assessment in a health maintenance organization in Belo Horizonte, Minas Gerais State, Brazil. Cad Saude Publica. 2013;29(suppl 1):73-80. 
25. Sorde M, Mourão LF, Silva LBC. Rheological behavior and labels of texture-modified foods and thickened fluids as used for dysphasia's services. Rev. CEFAC. 2012;14(5):925-32.
26. Morais HCC, Gonzaga NC, Aquino PDS, Araújo TLD. Strategies for self-management support by patients with stroke: integrative review. Rev Esc Enferm USP. 2015;49(1):136-43. 